\title{
PeRMANÊNCIA NA EJA: O QUE NOS DIZEM OS JOVENS E ADULTOS ESTUDANTES DA ZONA RURAL DE SOBRAL
}

\author{
Francisco Josimar Ricardo XaVier \\ AdRIANo Vargas FreItAS \\ Universidade Federal Fluminense (UFF), Niterói, Rio de Janeiro, Brasil
}

\begin{abstract}
Resumo: Este artigo traz um recorte das análises de pesquisa que tem como objetivo compreender as motivações e os sentidos que estudantes de Educação de Jovens e Adultos (EJA) oferecem para a sua permanência em uma escola municipal da zona rural de Sobral. Como instrumento de coleta de dados, utilizamos a entrevista semiestruturada, aplicada a 4 estudantes de uma turma multisseriada dos anos do ensino fundamental, dos quais captamos respostas que foram analisadas por meio da técnica de Análise Textual Discursiva. Nos resultados apuramos que as relações afetivas entre estudantes, entre eles e a professora e a prática pedagógica adotada são alguns fatores que motivam os estudantes a permanecerem na escola.
\end{abstract}

Palavras-chave: EJA. Permanência. Motivações. Escola de zona rural.

INTRODUÇÃO

$\mathrm{O}$ atual contexto político e social em que se encontram os brasileiros tem suscitado reflexões acerca da efetivação dos seus direitos subjetivos, informados na Constituição Federal de 1988 (BRASIL, 1988). Entre tais direitos, está o que diz respeito à Educação, alimentado por algumas alterações promovidas por leis, decretos e reformas que têm colocado em xeque as discussões sobre a igualdade de acesso e a permanência da população mais pobre em "instituições próprias" de ensino (BRASIL, 1996, p. 8).

Dentre algumas dessas alterações, podemos destacar a reforma da previdência social, a reforma trabalhista e a reforma do Ensino Médio. As primeiras, segundo Frigotto (2016, p. 1), tiveram como objetivo "recolocar as populações pobres, trabalhadoras do campo e da cidade em situações austeras de sobrevivência", já a última teve como papel legalizar "a existência de uma escola diferente para cada classe social" (id. ibid.). Some-se a isso o congelamento de investimentos na Educação, que tem surtido efeitos negativos, e o desmonte de instituições de ensino básico e superior. Uma "agressão frontal à Constituição de 1988 e à Lei de Diretrizes da Educação Nacional" (FRIGOTTO, 2016, p. 1).

Especificamente sobre a Educação de Jovens e Adultos (EJA), reconhecemos que a presença dessa modalidade da Educação Básica, no contexto atual, reafirma as lutas que trazem um legado histórico, como a parte dos sistemas de ensino que a todo custo resiste ao caos educacional (JARDILINO; ARAÚJO, 2014). Percebemos essa resistência quando, mediante as leituras dos trabalhos para a nossa revisão de literatura e da construção do aporte teórico, verificamos ainda existir certo descaso das políticas educacionais nacionais em relação à EJA. Nesse contexto, ela passa a ser vista como algo 
à parte da escolarização regular, resumida a um regime de suplência ou de atendimentos aligeirados.

Percebemos também que esse pensamento ainda está presente no imaginário social de pessoas que desconhecem as políticas de EJA. Desde professores que ainda atuam com práticas pedagógicas ${ }^{1}$ assistencialistas e até os poderes políticos locais que consideram, em geral, como gasto o investimento financeiro nessa modalidade educacional. Compreendemos que todos esses aspectos atuam conjuntamente para a reprodução de discursos que fazem da escola pública alvo de taxamentos negativos, especialmente as turmas de $E J A$, por serem consideradas menos importantes que àquelas ditas "regulares". Ainda assim, há estudantes e professores que optam por continuar nelas estudando e lecionando.

Acreditando existir outras maneiras de pensar a educação voltada para jovens e adultos e motivados por um estranhamento ${ }^{2}$ dado em uma turma de EJA em uma escola municipal da zona rural de Sobral, cidade do interior do Ceará, empreendemos a nossa pesquisa de Mestrado em Educação. $O$ referido estranhamento ocorreu porque professores de EJA, dentre esses alguns mais experientes, pregavam discursos alegando pouca quantidade e baixa frequência de estudantes nas turmas, enquanto observamos que havia um número significativo de estudantes, se comparássemos os frequentes/presentes e o total de matriculados na escola. Disso resultou nosso interesse em pesquisar a permanência na EJA. Nosso objetivo é compreender as motivações e os sentidos que os estudantes da EJA oferecem para permanecerem na escola.

Destacamos que nosso estudo se concentra no espaço de discussão da educação escolar, especificamente, sobre sujeitos jovens e adultos em processo de escolarização, em turmas noturnas de curso de EJA presencial de uma escola que tem determinações, regimentos administrativos e pedagógicos próprios. Portanto, com uma categoria organizacional estruturada que contempla em seu interior, uma heterogeneidade cultural composta por sujeitos com vivências, experiências e histórias diversas (OLIVEIRA, 1999).

Acreditamos que a diversidade da EJA é o fator que a distingue, permitindo-nos uma reflexão, pois seus estudantes têm motivos de chegada e de permanência na escola que diferem daqueles do ensino regular. Como tais motivos são específicos, podem ser influenciados por fatores externos e internos ao espaço escolar e, por isso, precisam ser problematizados considerando a contextualização social desses "outros sujeitos" (ARROYO, 2014, p. 25). A resistência desses alunos que se fazem presentes nos bancos escolares noturnos nos permite indagar sobre a escola que temos, qual o sentido dela e como ela atende às suas necessidades.

Neste artigo lançamos mão de discussões sobre alguns dados de nossa pesquisa, mas sem a pretensão de esgotar o debate que possa advir dos mesmos. Assim, no intuito de melhor apresentarmos os dados e discussões, optamos por articular nosso texto em blocos, a saber: um primeiro, que denominamos: "Quem são os estudantes da EJA?", onde apontamos uma breve caracterização do público a quem se destinou e se destina a educação de jovens e adultos; um segundo, intitulado: "Percurso trilhado na pesquisa", no qual destacamos o perfil da escola lócus, dos estudantes sujeitos da 
XAVIER, F. J. R.; FREITAS, A. V.

pesquisa, os instrumentos de coleta de dados e a Análise Textual Discursiva por nós realizada. Já no bloco: "O que nos dizem os estudantes da EJA da zona rural de Sobral", trazemos nossos resultados e discussões. Por fim, tecemos nossas considerações finais.

\title{
QUEM SÃO OS ESTUDANTES DA EJA?
}

Ao discorrermos sobre educação de jovens e adultos, faz-se necessário trazer a especificidade de "onde" e de "quem" se está falando. Neste este bloco centramos nossas discussões sobre "quem" são essas pessoas.

Como nos informa Fonseca (2012), podemos dizer que não nos referimos a jovens e adultos que estão nos bancos universitários nos cursos de graduação ou pósgraduação ou que estão cursando as séries escolares na idade certa. Referimo-nos, de acordo com Galvão e Di Pierro (2013), a sujeitos, em geral, pertencentes aos estratos sociais de baixa renda, cujo direito à educação foi violado na infância ou na adolescência. São eles também,

\begin{abstract}
geralmente o migrante que chega às grandes metrópoles provenientes de áreas rurais empobrecidas, filho de trabalhadores rurais não qualificados e com baixo nível de instrução escolar (muito freqüentemente analfabetos), ele próprio com uma passagem curta e não sistemática pela escola e trabalhando em ocupações urbanas não qualificadas, após experiência no trabalho rural na infância e na adolescência, que busca a escola tardiamente para alfabetizar- se ou cursar algumas séries do ensino supletivo (OLIVEIRA, 1999, p. 59).
\end{abstract}

Muitos desses sujeitos têm que se desdobrar no trabalho durante o dia, para então, à noite, estarem presentes à sala de aula, em um ambiente muitas vezes não acolhedor. Para Arroyo (2017, p. 39), são eles "os passageiros da noite" que se afirmam, cada vez mais, como "sujeitos de novas identidades coletivas, positivas, produtoras de outros espaços nas cidades e nos campos em suas lutas" (id. ibid.). Estão mais presentes nos espaços de ensino "existentes, reagindo a seu silenciamento e ocultamento. Reagindo às formas de ser pensados e tratados, de ser subordinalizados nas relações de poder, dominação" (id. 2014, p. 37), não se deixando mais ser silenciados pelas pedagogias escolares. Essas que, muitas vezes, limitam-se a conhecê-los como pessoas fora da faixa etária e "idade própria" (BRASIL, 1996, p. 9) para frequentar as séries regulares ou como um número, uma média a ser alcançada.

Falamos de sujeitos alfabetizados no mundo, no sentido de saberem-se conscientes de seus direitos e de que sua presença na escola não é contrapartida de um favor concedido por caridade, mas a efetivação de uma responsabilização política. Dessa maneira, tecemos interpretações sobre os estudantes da EJA à luz também do entendimento de Freire (1987), para quem os jovens e adultos detêm conhecimentos provenientes de suas vivências e que esses precedem os saberes escolares, devendo ser incorporados às propostas pedagógicas dos sistemas de ensino e escolas. Por terem experiências de vida calcadas em disputas sociais, por se reconhecerem enquanto sujeitos que têm direito à educação e demais políticas sociais básicas, podemos considerá-los como jovens e adultos politicamente alfabetizados. 


\section{O PERCURSO TRILHADO NA PESQUISA}

Este tópico apresenta o percurso que trilhamos para a construção de nossa pesquisa. Em uma leitura ampla, podemos destacar que ela foi organizada em duas variantes ${ }^{3}$ : uma variante externa à sala de aula e outra variante interna à sala de aula, as quais foram constituídas pelas etapas específicas da pesquisa.

Os dados aqui apresentados compuseram a variante interna à sala de aula que correspondeu, dentre outros momentos, a aplicação dos questionários e realização de entrevistas com professores e estudantes. No intuito de situar o leitor no campo estudado, apresentamos aqui o perfil da escola, dos estudantes da EJA e a metodologia utilizada para a concretização da pesquisa, destacando os instrumentos de coleta e a técnica de análise de dados.

Quem são e onde estão os sujeitos, jovens e adultos, a que nos referimos neste artigo? Destacamos que buscar compreendê-los e conhecê-los foram outros fatores que reforçaram a motivação para nos aprofundarmos na pesquisa sobre a EJA. Conhecê-los não apenas como estudantes de uma área geográfica de difícil acesso, mas como sujeitos que, por trás das especificidades de ser homem ou mulher, jovem ou adulto, moradores da zona rural, têm histórias de vidas que influenciam o seu "estar na escola".

Nesse sentido, coube-nos familiarizar, primeiramente, com a escola em que estão matriculados esses jovens e adultos. Assim, tivemos como lócus de nossa pesquisa a Escola Municipal de Educação Infantil e Ensino Fundamental, situada em um Distrito, na zona rural, localizado a $07 \mathrm{~km}$ da cidade de Sobral. De acordo com o seu Regimento Escolar (SOBRAL, 2017a), ela atende as etapas: Educação Infantil e Ensino Fundamental, nos turnos diurnos, e EJA, no turno noturno.

A referida escola é do tipo nucleada 4 , com a sede considerada para o Ministério da Educação (MEC) e para a Secretaria Municipal de Educação (SEDUC - Sobral) localizada na zona urbana e os edifícios extensões, localizados na zona rural, que abrigam turmas de séries regulares e turmas de EJA. A Lei Municipal no 492/2004, em seu artigo 4, faculta a denominação desses edifícios que abrigam turmas na zona rural das escolas nucleadas. Tal denominação não exime a escola-sede dos apoios que deve oferecer a essas turmas, visa apenas reforçar os edifícios extensões como "partes integrantes e indissociáveis da unidade escolar autônoma" a que estão vinculados (SOBRAL, 2004, p. 4). A leitura deste artigo $4^{\circ}$, possibilitou-nos compreender melhor as extensões da referida escola municipal que estão situadas em 4 localidades que denominamos de A, B, C e D. Em todas as extensões há turmas de EJA multisseriadas formadas por estudantes moradores das referidas localidades.

Segundo o Projeto Político Pedagógico (SOBRAL, 2017b) da escola, essas unidades possuem turmas multisseriadas da modalidade EJA do Primeiro Segmento, com os níveis EJA I e EJA II, e no Segundo Segmento, com os níveis EJA III e EJA IV. Portanto, consideramos ser possível a convivência de estudantes da EJA I ( $1^{\circ}, 2^{\circ}$ e $3^{\circ}$ anos), EJA II (4० e $5^{\circ}$ anos), EJA III ( $6^{\circ}$ e $7^{\circ}$ anos) e EJA IV ( $8^{\circ}$ e $9^{\circ}$ anos) em uma mesma turma.

Acerca da situação da EJA nessa escola, a quantidade de matrículas da modalidade varia a cada ano, dado o período de 2010 a 2017, por nós pesquisado na 
plataforma QEdu 5 . O ano de 2012 chegou a ter 152 matrículas, um percentual de 29,28\% do total de estudantes da escola. $O$ ano de menor porcentagem foi 2011, com 78 estudantes matriculados, correspondendo a $17,37 \%$ do total da escola. Tais dados apresentam-se na Tabela 1.

Tabela 1 - Quantitativo de matrículas na escola pesquisada

\begin{tabular}{ccccccccc}
\hline Ano & Creche & $\begin{array}{c}\text { Pré- } \\
\text { Escola }\end{array}$ & $\begin{array}{c}\text { Fund. } \\
\text { Inicial }\end{array}$ & $\begin{array}{c}\text { Fund. } \\
\text { Final }\end{array}$ & EJA & $\begin{array}{c}\text { Educação } \\
\text { Especial }\end{array}$ & Total & $\begin{array}{c}\% \\
\text { EJA }\end{array}$ \\
\hline 2010 & 0 & 25 & 162 & 145 & 79 & 0 & 411 & 19,22 \\
2011 & 17 & 58 & 150 & 146 & 78 & 0 & 449 & 17,37 \\
2012 & 23 & 64 & 153 & 127 & 152 & 0 & 519 & 29,28 \\
2013 & 15 & 56 & 149 & 131 & 76 & 0 & 427 & 17,79 \\
2014 & 57 & 46 & 158 & 114 & 84 & 0 & 459 & 18,30 \\
2015 & 57 & 48 & 152 & 115 & 107 & 0 & 479 & 22,33 \\
2016 & 51 & 63 & 145 & 113 & 92 & 0 & 464 & 19,82 \\
2017 & 61 & 63 & 144 & 116 & 125 & 0 & 509 & 24,55 \\
2018 & 65 & 64 & 162 & 114 & 131 & 0 & 536 & 24,44 \\
\hline
\end{tabular}

Fonte: Tabela elaborada a partir da base de dados da Plataforma QEdu. Disponível em: <http://www.qedu.org.br/cidade>. Acesso em: 07 out. 2017. Atualizada com os dados cedidos pela diretora escolar, em fevereiro de 2018.

De acordo com a tabela de matrículas da EJA, cedida pela diretora da escola pesquisada, no dia 22 de janeiro de 2018 , constatou-se que nesta escola no ano letivo de 2018, existiam 5 turmas multisseriadas de EJA, atendidas nas localidades anteriormente citadas. A Tabela 2 mostra o perfil geral dos estudantes das turmas de EJA da escola pesquisada.

Tabela 2 - Perfil dos estudantes da EJA da escola pesquisada

\begin{tabular}{c|cccc|c|cccc}
\hline \multirow{2}{*}{ Sexo } & \multicolumn{4}{|c}{ Nível de EJA } & Total & \multicolumn{4}{|c}{ Faixa etária } \\
\cline { 2 - 10 } & I & II & III & IV & & $15-30$ & $31-45$ & $46-60$ & $61-75$ \\
\hline Mulher & 7 & 19 & 14 & 21 & 61 & 9 & 31 & 21 & 0 \\
Homem & 17 & 11 & 16 & 26 & 70 & 13 & 36 & 19 & 2 \\
\hline Total & $\mathbf{2 4}$ & $\mathbf{3 0}$ & $\mathbf{2 3}$ & $\mathbf{4 6}$ & $\mathbf{1 3 1}$ & $\mathbf{2 2}$ & $\mathbf{6 7}$ & $\mathbf{4 0}$ & $\mathbf{2}$ \\
\hline
\end{tabular}

Fonte: Dados codificados pelos pesquisadores.

Analisando a Tabela 2 podemos concluir que, para ano letivo de 2018, há 131 estudantes nas turmas multisseriadas de EJA na escola. Destes, 70 (pouco mais de 53\%) são do sexo masculino, dos quais 42 concluirão o Segundo Segmento da EJA (EJA III e EJA IV), o correspondente a $60 \%$ do total de estudantes homens. Já as mulheres, constituem o universo de 61 estudantes de EJA (aproximadamente 47\%). Dessas, 35 concluirão também o Segundo Segmento de EJA, o correspondente a pouco mais $57 \%$ do total de estudantes mulheres.

No que diz respeito à idade, os estudantes homens concentram-se na faixa entre 31 e 45 anos, totalizando 36 alunos (o correspondente a 51,4\% de 70 estudantes homens). 
As mulheres da mesma faixa etária são maioria entre as estudantes, com o total de 31 alunas (o correspondente a 50,8\% de 61 estudantes mulheres). É importante ressaltar que, embora prevaleça maior número de homens nas turmas, constatamos a maciça presença de mulheres, que foram as que mais frequentaram o ano letivo de 2017, segundo análise que fizemos dos diários de classe das turmas de EJA daquele ano letivo. Foram elas também as que mais continuaram frequentando a escola no ano de 2018, de acordo com nossas observações em sala de aula nesse último ano.

Finalizamos este tópico com a compreensão de que os números aqui apresentados não se relacionam diretamente à permanência, tampouco, às motivações que levam os estudantes a continuarem frequentando a escola. Todavia, eles forneceram elementos para a nossa análise comparativa entre quantidade de matriculados e evadidos, ponto essencial à definição da turma a ser observada e, dentro dessa, à definição dos estudantes a serem entrevistados.

\section{O PERFIL DOS ESTUDANTES PESQUISADOS}

Os estudantes que são informantes-chave ${ }^{6}$ desta pesquisa foram selecionados em um encontro com o orientador do turno da noite ${ }^{7}$, no dia 11 de janeiro de 2018. A seleção resultou da análise dos diários de classes das turmas de EJA da escola do ano de 2017. Para a escolha dos estudantes utilizamos dois critérios: 1) menor quantidade de faltas durante o ano letivo de 2017 e 2) não deveria ser estudante da EJA IV, no ano de 2017. Este último critério foi estabelecido porque sendo estudante do nível de EJA IV, possivelmente ele não estaria mais na escola no ano de 2018.

Frisamos que no ano letivo de 2017, a escola pesquisada contou com 5 turmas de EJA. Contudo, os professores que lecionavam nessas turmas mantinham contrato temporário com a SEDUC - Sobral e por isso tiveram que passar por um processo seletivo de provas e títulos para que seus contratos fossem renovados. Dos 5 professores, apenas duas professoras passaram no processo seletivo. Elas tinham lecionado nas turmas Multi EJA "A" e Multi EJA "B" em 2017 e assim continuariam em 2018. Como pretendíamos observar também as práticas dos professores, definimos que seriam essas duas docentes as nossas informantes-chave dos Professores de EJA. Essa definição incidiu na decisão de eleger as suas respectivas turmas para nosso acompanhamento e observações, além de ter seus estudantes mais frequentes como nossos outros sujeitos de pesquisa.

Assim, este artigo versa sobre os resultados das entrevistas realizadas com os 4 estudantes mais frequentes da turma Multi EJA " $B$ " e que estão atualmente matriculados. No intuito de preservar as identidades dos estudantes, eles serão nomeados ao longo deste texto por En, onde E representa a palavra "estudante" e $n$, o algarismo que o codificamos. O Quadro 1 traça o perfil dos estudantes. 
Quadro 1 - Perfil dos estudantes da EJA entrevistados ${ }^{8}$

\begin{tabular}{|c|c|c|c|c|c|}
\hline Estudante & Sexo & Idade & Cor & Estado Civil & Tempo na EJA \\
\hline E1 & M & 53 & Parda & Desquitado & 4 anos \\
\hline E2 & M & 42 & Parda & Casado & 2 anos \\
\hline E3 & F & 33 & Parda & Casada & 3 anos \\
\hline E4 & F & 55 & Parda & Solteira & 4 anos \\
\hline
\end{tabular}

Fonte: Quadro elaborado pelos pesquisadores.

\section{MetOdOLOGIA}

Definimos a observação participante e a entrevista semiestruturada (GIL, 2008) como nossos instrumentos de coleta de dados. Para análise dos dados, propomos fazer uma Análise Textual Discursiva9 (MORAES; GALIAZZI, 2016), com a qual relacionamos, qualitativamente, os dados e as informações concedidos pelos sujeitos envolvidos, o referencial teórico estudado e a nossa percepção enquanto pesquisadores.

Especificamos que os dados aqui analisados dizem respeito às transcrições das entrevistas com os estudantes, nas quais buscamos compreender as motivações e os sentidos que eles oferecem para sua permanência na escola. Ademais, dentre as temáticas estudadas ${ }^{10}$ na pesquisa, focaremos nossas discussões sobre a Permanência na EJA.

Atentando-se à apresentação dos dados e análise, elaboramos quadros onde dispusemos as respostas dos estudantes. Nessas respostas destacamos algumas palavras a partir das quais captamos as possíveis motivações que os fazem "estar" em sala de aula e um sentido de permanência que perpassasse nessas motivações. Diante disso, aproximamos os resultados obtidos às leituras de nosso aporte teórico e a nossa percepção enquanto pesquisadores, elaborando nossos metatextos ${ }^{11}$ que são apresentados no bloco a seguir.

\section{O QUE NOS DIZEM OS ESTUDANTES DA EJA DA ZONA RURAL DE SOBRAL}

Este bloco trata dos resultados e discussões feitos sobre as respostas dos estudantes da turma Multi EJA B. Frisamos que o roteiro de entrevista que seguimos foi composto de algumas perguntas específicas a cada temática estudada em nossa pesquisa. Contudo, para este artigo nos debruçamos apenas sobre duas questões: "O que motiva você a estar na sala de aula da EJA?" " "Como as aulas de EJA contribuem para sua vida?", o que nos permitiu discutir a temática Permanência na EJA.

Optamos por analisar as respostas separadamente, o que resultou na elaboração dos dois metatextos que são apresentados nos tópicos deste bloco. Esclarecemos que o limite estrutural do artigo, bem como o foco que decidimos direcionar, impossibilitou-nos de empreendermos outros vieses de discussões que, possivelmente, possam surgir a partir da realização de novas leituras.

Empenhados no objetivo de nossa pesquisa, buscamos compreender as motivações que fazem cada um desses estudantes "estar" na escola. Com isso, 
elaboramos a seguinte pergunta em nosso roteiro de entrevista: "O que motiva você a estar na sala de aula da EJA?"

O Quadro 2 apresenta as respostas dos estudantes e as palavras que destacamos para fins de análise.

Quadro 2 - Motivação para os estudantes estarem na escola na EJA da zona rural

\begin{tabular}{|c|c|c|}
\hline Estudante & Respostas & Palavras \\
\hline E1 & $\begin{array}{l}\text { Aprender. Aprender é bom né, por que eu vou desenvolver } \\
\text { mais a cabeça. Conhecer outras pessoas diferentes. Eu sou } \\
\text { curioso, também tenho o desejo de aprender muito. Tem um } \\
\text { bucado de gente aqui, senhoras mais velhas, que eu vejo } \\
\text { também estudando. E a professora é gente boa. }\end{array}$ & $\begin{array}{l}\text { Aprender } \\
\text { Vontade } \\
\text { Desejo } \\
\text { Curioso } \\
\text { Professora }\end{array}$ \\
\hline E2 & $\begin{array}{l}\text { Eu quero aprender mais um pouco. Tai, minha esposa tirou } \\
\text { habilitação, ai ela fala: E2 estuda pra tu tirar a tua, ai eu } \\
\text { continuo, continuo, ai na hora eu desisto. Eu sou assim. }\end{array}$ & $\begin{array}{l}\text { Aprender } \\
\text { Tirar a carteira de } \\
\text { habilitação }\end{array}$ \\
\hline E3 & $\begin{array}{l}\text { Meus filhos. Pra eu ajudar eles mais na frente nas atividades } \\
\text { da escola, pra quando eles me perguntar, mãe o que é isso, } \\
\text { eu dizer, eu sei, eu estudei, aprendi. E a professora é muito } \\
\text { bacana, ela diz, se você não souber E3, você pergunte, isso é } \\
\text { bom. }\end{array}$ & $\begin{array}{l}\text { Aprendi } \\
\text { Filhos } \\
\text { Professora }\end{array}$ \\
\hline E4 & $\begin{array}{l}\text { É que eu quero aprender né. A gente vai lá, a professora } \\
\text { ensina. Tem as conversação também. A gente fica entretido. } \\
\text { Eu gosto da professora, mas gosto mais do ensino dela. Um } \\
\text { dia eu assisti na televisão uma mulher de sessenta e cinco } \\
\text { ano, no EJA a noite, ela tava fazendo o vestibular. Eu fiquei } \\
\text { admirada. Ela fazendo o vestibular. E eu pensei assim, meu } \\
\text { Deus do céu, eu vou pra escola. Ai eu comecei a ir. }\end{array}$ & $\begin{array}{l}\text { Aprender } \\
\text { Professora } \\
\text { Ensino } \\
\text { Conversação } \\
\text { Entretido }\end{array}$ \\
\hline
\end{tabular}

Fonte: Quadro elaborado pelos pesquisadores.

A partir da leitura da coluna "Palavras", constatamos que "aprender" destacase em todas as respostas. Já na coluna "Respostas", percebemos que o termo "aprender" está associado a um desejo de realização pessoal como "conhecer outras pessoas diferentes" (E1) ou porque, existindo uma relação afetiva, de "conversação", na sala de aula, o desejo de "aprender" é aflorado pela estudante (E4). Além disso, compreendemos que o "aprender" também é movido pelo desejo de realizações futuras como "tirar a carteira de habilitação" (E2) ou para "ajudar" os filhos nas atividades escolares (E3).

Como nos informa Cipiniuk (2017), é possível que a vontade, o desejo de aprender desses estudantes já esteja mobilizado antes mesmo de eles afiliarem-se à unidade de ensino, sendo o seu "estar" na escola movido, dentre outros fatores, pelo "aprendizado da leitura e da escrita" (id. p. 89) e, complementamos, com a aprendizagem da "matemática escolar" (FONSECA, 2012, p. 28).

Entendemos haver relação entre o tempo de vivência e experiência dos estudantes e suas respostas; por isso, analisamos essas sob o prisma de suas idades e do seu tempo de estudo na EJA. Constatamos que os estudantes que têm mais idade (E1 e E4) e estão há mais tempo na EJA têm motivações específicas para destacar seu 
"aprender" e o seu "estar" na escola; assim como os mais jovens (E2 e E3), que têm menos tempo de EJA, possuem outras motivações.

Um ponto que merece destaque nas respostas dos estudantes é a presença da "professora" (E1, E3 e E4). A leitura das falas captadas nos possibilita compreender que existe uma boa relação entre a professora da turma e os estudantes, bem como a forma como ela estabelece a prática pedagógica. Essa prática, que eles entendem como "ensino", parece ser capaz de atingir o objetivo particular de cada um para o seu "estar" em sala de aula. Entendemos também que, essa boa relação tem influência sobre a permanência dos estudantes na escola. De outra forma, consideramos ser possível admitir que se não houvesse uma boa relação com a professora e mesmo se ela não tivesse uma prática pedagógica que correspondesse às suas expectativas, os estudantes estariam fora dos bancos escolares.

Tomando por base o estudo de Fonseca (2012, p. 47- 48, grifo da autora), compreendemos que as motivações para os estudantes estarem na escola articulam-se dentro do que a referida autora chama de "motivações externas" e "motivações internas". A saber: as primeiras englobam as "pressões da vida social" (id. ibid), como a busca pela "ascensão na empresa, maior exigência da escolaridade, conquistar profissão mais valorizada", entre outras. Das respostas aqui analisadas, destacamos para esse grupo as do estudante E2, que nos aponta que seu "estar" na escola para "aprender", é motivado pelo desejo de tirar a carteira de habilitação.

As demais respostas analisadas estão agrupadas dentro das "motivações internas" (FONSECA, 2012, p. 48, grifo da autora) que, segundo a autora, dizem respeito aos estudantes que estão na escola para cuidar de si, de seus filhos, porque querem se sentir melhor, entre outras. Desta forma, entendemos que nesse grupo enquadram-se as respostas dos estudantes $E 1$, que relata que estar na escola para aprender e, quem sabe, "conhecer mais gente diferente"; da estudante E3, que diz estar na escola para aprender para poder acompanhar os "filhos" nas tarefas escolares em casa e de E4, que diz estar na escola porque a entende como um lugar para ocupar a mente, estar "entretido" junto dos colegas.

Compreendemos que as motivações apresentadas pelos estudantes partem também de exemplos e vivências de pessoas próximas ou que foram vistos em algum lugar, para falar de seus "estar" na escola. São estes: "as senhoras mais velhas também presentes na escola" (E1); a "minha esposa tirou a habilitação" (E2), o fato de os "meus filhos pra eu ajudar eles mais na frente nas atividades da escola" (E3) e "um dia eu assisti na televisão uma mulher de sessenta e cinco ano, no EJA a noite, ela tava fazendo o vestibular"(E4).

De uma maneira geral, independente da idade, entendemos que tais motivações, vêm carregadas do sentimento de pertencimento. $O$ que, segundo Fávero analisado por Carmo e Silva (2016), nos diz que esse sentimento está ligado ao fato de que os estudantes mais adultos e, principalmente, os idosos, voltam e permanecem na escola porque o ensino lhes fez falta na vida.

\section{UM SENTIDO PARA A PERMANÊNCIA DOS ESTUDANTES NA ESCOLA}


Neste tópico buscamos elucidar e compreender o sentido da permanência nas falas dos estudantes a partir de suas respostas para as perguntas elaboradas em nosso roteiro de entrevista. As respostas dos alunos sobre o que os motivam a "estar" na escola já nos dão pistas para entendermos de que há algo para além do "aprender" que os prendem à instituição própria de ensino (BRASIL, 1988). Este "aprender", por todos citados, veio complementado pelo "ensino", representado pela figura da "professora", mas também veio atrelado à "vontade", ao "desejo" de querer e às relações existentes no espaço da sala de aula.

No intuito de captar o sentido de permanência, somamos às perguntas do roteiro de entrevista, mais uma questão em que pudéssemos entender o ponto de vista dos estudantes sobre a relação "escola-vida" fora da escola. Nesse sentido, perguntamos: "Como as aulas da EJA contribuem para sua vida?"

As respostas captadas foram agrupadas no Quadro 3 abaixo, onde destacamos algumas palavras, a partir das quais analisamos um possível sentido de permanência dos estudantes na EJA.

Quadro 3 - Contribuições das aulas da EJA para a vida dos estudantes

\begin{tabular}{|c|c|c|}
\hline Estudante & Resposta & Palavras \\
\hline E1 & $\begin{array}{l}\text { Contribui com muita coisa. Tem coisa que eu não sabia nada. } \\
\text { Eu era um cego. Eu to muito feliz de estar aqui, aprender os } \\
\text { conhecimentos. A professora é boa. }\end{array}$ & $\begin{array}{c}\text { Aprender } \\
\text { Conhecimentos } \\
\text { Feliz }\end{array}$ \\
\hline E2 & $\begin{array}{l}\text { Eu acho que contribui muito para a minha vida. É uma coisa } \\
\text { que eu quero aprender, aprender a ler, escrever, as contas. A } \\
\text { minha menina, se você der qualquer papel ela lê. Eu vejo ela } \\
\text { lendo assim, minha mulher manda eu ler, ai eu não. Fico lá só } \\
\text { observando. }\end{array}$ & $\begin{array}{l}\text { Aprender } \\
\text { Vida } \\
\text { Ler } \\
\text { Escrever }\end{array}$ \\
\hline E3 & $\begin{array}{l}\text { Assim, muitas pessoas acham que não contribuem, mas eu } \\
\text { aprendo muito na EJA. Eu gosto de fazer amizades na escola. } \\
\text { Meu problema é ser sensível e tímida na sala. Âs vezes eu faço } \\
\text { uma conta de matemática e apago, ai ta errada, eu vou apagar. } \\
\text { Ai quando eu vou olhar ta certo. Então contribui por que eu } \\
\text { aprendo mais. }\end{array}$ & $\begin{array}{c}\text { Aprendo } \\
\text { Fazer amizades }\end{array}$ \\
\hline E4 & $\begin{array}{l}\text { Ah por que eu aprendi demais. Eu não sabia de nada. Tinha } \\
\text { atividade que a professora mandava fazer a família, o bê com } \\
\text { á, ai ela mandava fazer. Uma coisa que eu não sabia. E as } \\
\text { continhas que ela fazia, aqui e acolá eu destrinchava alguma. } \\
\text { A professora a passa no caderno, pra explicar. Eu gosto da } \\
\text { escola. }\end{array}$ & $\begin{array}{l}\text { Aprendi } \\
\text { Continhas } \\
\text { Gosta da escola }\end{array}$ \\
\hline
\end{tabular}

Fonte: Quadro elaborado pelos pesquisadores.

Em leitura da coluna "Palavras" percebemos que o verbo "aprender" e suas conjugações temporais apresentam-se como dominantes. A coluna "Respostas" reafirma esta presença do "aprender", ligado ao "ensino" no sentido de "conhecimentos" (E1), "ler, escrever, as contas" (E2), "conta de matemática" (E3) ou o "bê com á" (E4). 
Tomando por base essa análise, relacionando os dados da coluna "Tempo na EJA" do Quadro 1, percebemos que, embora as motivações para estar na escola sejam específicas e tenham influência das experiências de vida dos estudantes, as motivações deles também se dão pela busca dos saberes escolares. Compreendemos que, para os alunos, a aquisição de esses saberes pode contribuir para atingir seus objetivos, independente do tempo em que estão ou ficarão na escola.

A busca pelos saberes escolares, somada ao sentimento de "estar muito feliz" (E1), porque em algum momento este "saber" pode contribuir para sua "vida" (E2) por estar na escola porque é um espaço onde se pode "fazer amizade" (E3) ou apenas porque "gosta" da escola (E4), possibilita-nos compreender um sentido de permanência para além do "estar" sentado dentro da sala de aula. Percebemos, assim como Reis (2016, p. 74), a permanência como "o ato de durar no tempo, que possibilita não só a constância do indivíduo, como também a possibilidade de transformação e existência".

Entendemos que o "durar no tempo" refere-se ao prazo de conclusão de um curso, de estada no espaço escolar, por exemplo. O que, de acordo com Reis (2016), está diretamente relacionado à trajetória que o estudante desenvolverá ao longo de sua vida escolar e, "depende, sobretudo, das condições para efetivação dessa trajetória" (id. p. 75). Por sua vez, compreendemos que é nos meandros do percurso da vida escolar que vão sendo tecidas as "transformações" no estudante, no sentido de ele se compreender enquanto sujeito. Conforme apresenta Reis (2016, p. 74), "a permanência deve ter caráter de existir em constante fazer e, desse modo, ser sempre transformação".

De uma maneira geral, analisamos que os estudantes da EJA da zona rural de Sobral, ao afirmarem-se presentes e permanentes na escola, mostram-se resistentes ao caos na educação e no ensino. Estão eles na EJA, como pudemos verificar, mais pelas relações afetivas entre seus pares e suas motivações internas do que, por exemplo, pelo diploma, pela merenda ou pela estrutura física da escola. Reconhecemos que esses últimos fatores, que também Ihes são de direito e não podem ser negligenciados, por serem as motivações de estudantes de outras realidades que precisam ser levadas em consideração.

Finalizamos este tópico com a compreensão de que, embora exista uma vasta literatura na pesquisa da área da Educação que busca explicar as motivações da evasão escolar de estudantes (OLIVEIRA, 1999), ainda faltam mais estudos focados no que os fazem permanecer na escola. Assim, podemos contribuir para a elaboração de políticas afirmativas que visem à permanência, sobretudo dos estudantes da EJA na escola e, quem sabe, para a superação das desigualdades sociais.

\section{CONSIDERAÇÕES FINAIS}

Este artigo teve como objetivo apresentar alguns fatores de motivação e o sentido de permanência que estudantes, jovens e adultos, oferecem para seus "estar" em uma escola municipal de ensino fundamental de EJA da zona rural de Sobral, no Ceará. Destacamos que os dados aqui apresentados referem-se ao grupo de estudantes que fez parte de nossa pesquisa. Tendo em vista a especificidade dos sujeitos, bem como do contexto em que estão inseridos, compreendemos que as motivações por eles apresentadas são inerentes às suas realidades socioeconômicas e culturais. 
De maneira geral, entendemos que os estudantes, independente da idade, apresentam fatores de motivação que estão ligados, principalmente, à afetividade construída no local de ensino que vêm carregadas do sentimento de pertencimento a esse espaço. Junte-se a isso o fato de buscarem também a aquisição de saberes da leitura e da matemática, quando expressam "estar" na escola por causa do "ensino" da professora. $\mathrm{O}$ que nos permite $\mathrm{o}$ entendimento de que a prática pedagógica da professora, que leciona na turma em que os estudantes estão matriculados, influencia também na sua permanência na escola.

Encaminhamos estas conclusões entendendo que os estudantes de EJA da zona rural do Sobral têm razões e motivações para estar na escola que lhes são específicas quanto à sua condição humana de sujeito, idade e realização pessoal. Pode-se dizer que há um ponto em comum entre eles: o fato de estarem em um espaço de educação escolar aprendendo e que lhes permite enxergar uma transformação real em suas vidas futuras. É esta visão de futuro transformadora que acreditamos ser o fator crucial para pensarmos políticas de permanência na escola, sobretudo de jovens e adultos, sujeitos mais marcados pelas desigualdades sociais.

Artigo recebido em: 01/10/2018 Aprovado para publicação em: 05/12/2018

\section{PERMANENCE IN THE EJA: WHAT YOUNG PEOPLE AND ADULTS TELL US ABOUT THE SOUTHERN} RURAL AREA

ABSTRACT: This article presents a part of the research analyzes.lt aimed to understand the motivations and senses that students of EJA confer for their stay in a municipal school in the rural area of Sobral.As an instrument of data collection, we used the semi-structured interview.We apply to 4 students from a multi-grade class of elementary school years.Thus, we captured responses that were analyzed using the Discursive Textual Analysis technique.As results, we emphasize that affective relationships among students are among the reasons for continuing in school. There are also the reasons: affective relationships with the teacher and the pedagogical practices she uses.

KEYWORDS: EJA. Permanence. Motivations. School of rural area.

\section{PERMANENCIA EN LA EJA: QUÉ NOS DICEN LOS JÓVENES Y ADULTOS ESTUDIANTES DE LA ZONA RURAL DE SOBRAL}

RESUMEN: Este artículo presenta una parte de los análisis de investigación que tuvo como objetivo comprender las motivaciones y sentidos que los estudiantes de EJA confieren para su permanencia en una escuela municipal de la zona rural de Sobral.Como instrumento de recolección de datos, utilizamos la entrevista semiestructurada, aplicada a 4 estudiantes de una clase multiseraria de los años de la enseñanza fundamental.Así, captamos respuestas que fueron analizadas por medio de la 
XAVIER, F. J. R.; FREITAS, A. V.

técnica de Análisis textual Discursivo.Como resultados, destacamos que las relaciones afectivas entre estudiantes, entre éstos con la profesora y las prácticas pedagógicas de ésta son algunos factores que motivan a los estudiantes a estar en la escuela.

PALABRAS CLAVE: EJA. Permanencia. Motivaciones. Escuela de zonas rurales.

\section{NOTAS}

1) Entendemos prática pedagógica à luz dos estudos de Franco (2015) que a define como uma ação elaborada e mediada pedagogicamente pelo professor com a finalidade da aprendizagem dos estudantes.

2) Enquanto professores de EJA pregavam discursos alegando pouca quantidade e baixa frequência de estudantes nas turmas, observamos que havia um número significativo de alunos, se comparássemos os estudantes frequentes/presentes e o total de matriculados na escola. Disso resultou nosso interesse em pesquisar a permanência na EJA.

3) Definimos a variante externa e a variante interna à sala de aula, que são caminhos distintos articulados na pesquisa, mas que se cruzam ao final, nos resultados.

4) Em Sobral, considera-se escola nucleada, aquela que atende classe de Educação Infantil, Fundamental Inicial e EJA do tipo multisseriada. Essas classes, em sua maioria, localizam-se na zona rural, enquanto que a escola-polo fica na zona urbana. Por serem multisseriadas tais turmas são chamadas de Multi EJA.

5) Disponível em: <http://www.qedu.org.br/cidade> . Acesso em: 07 out. 2017.

6) Consideramos informantes-chave, os representantes de um grupo que pretendemos pesquisar.

7) Em Sobral, as escolas que possuem turmas de EJA, contam com uma mesma pessoa para a função de orientador que é responsável tanto pela parte administrativa quanto da pedagógica do programa.

8) Com exceção das colunas "ESTUDANTE" e "TEMPO NA EJA", as demais foram elaboradas tomando por base os critérios do "Questionário da Amostra", do Censo demográfico de 2010 do Instituto Brasileiro de Geografia e Estatística (IBGE). Disponível em <https://censo2010.ibge.gov.br/images/pdf/censo2010/questionarios/questionario_amostra_cd2 010.pdf $>$ Acesso em 17/05/017.

9) Segundo Moraes e Galiazzi (2016, p. 67), a Análise Textual Discursiva pode ser compreendida como "um processo auto-organizado de construção de novos significados em relação a determinados fenômenos, a partir de materiais textuais referentes a esses fenômenos".

10) Além da Permanência, a pesquisa como um todo abrange as temáticas Práticas Pedagógica, Currículo, Matemática e Etnomatemática. 
11) De acordo com Moraes e Galiazzi (2016), os metatextos são os resultados dos dados analisados e categorizados na Análise Textual Discursiva que correspondem ao que os autores chamam de captar o novo emergente.

\section{REFERÊNCIAS}

ARROYO, M. G. Outros Sujeitos, Outras Pedagogias. 2. ed. Petrópolis, RJ: Vozes, 2014.

ARROYO, M. G. Passageiros da noite: do trabalho para a EJA: itinerários pelo direito a uma vida justa. Petrópolis: Vozes, 2017.

BRASIL. Constituição Federal da República Federativa do Brasil. Senado Federal. 25 ed. Brasília, DF, 1988.

BRASIL. Lei n. 9394, de 20 de dezembro de 1996. Aprova a Lei de Diretrizes e Bases da Educação Nacional. Conselho Nacional de Educação/ Câmara de Educação Básica. Brasília, DF, 1996.

CARMO, G. T. do; SILVA, C. B. da. Da evasão/fracasso escola como objeto "sociomediático" à permanência como objeto de pesquisa: o anúncio de uma construção coletiva. In: CARMO, G. T. do (Org.). Sentido da permanência na educação de jovens e adultos: anúncio de uma construção coletiva. Rio de Janeiro: Tempo Brasileiro, 2016. p. 41-72.

CIPINIUK, T. A. Analfabeto: problema social e desonra pessoal. Niterói: Eduff/Faperj, 2017.

FONSECA, M. da C. F. R. Educação matemática de jovens e adultos. especificidades, desafios e contribuições. 3 ed. Belo Horizonte: Autêntica, 2012.

FRANCO, M. A.S. Práticas pedagógicas de ensinar-aprender: por entre resistências e resignações. Revista Educação e Pesquisa, São Paulo. v. 41, n. 3, p. 601-614, jul./ set. 2015.

FREIRE, P. Pedagogia do Oprimido. 17 ed. Rio de Janeiro: Paz e terra, 1987.

FRIGOTTO, G. Reforma do ensino médio do (des) governo de turno: decreta-se uma escola para os ricos e outra para os pobres. Disponível em $<$ http://www.anped.org.br/news/reforma-de-ensino-medio-do-des-governo-de-turnodecreta-se-uma-escola-para-os-ricos-e-outra> Acesso em: 04 maio 2018. 
XAVIER, F. J. R.; FREITAS, A. V.

GALVÃO, A. M. de O.; DI PIERRO, M. C. O preconceito contra o analfabeto. ed. 2. São Paulo: Cortez, 2013. (v. 2).

GIL, A. C. Métodos e técnicas de pesquisa social. 6. ed. São Paulo: Atlas, 2008.

JARDILINO, J. R. L; ARAÚJO, R. M. B. de. Educação de Jovens e Adultos: sujeitos, saberes e práticas. São paulo: Cortez, 2014.

MORAES, R.; GALIAZZI, M. do C. Análise Textual Discursiva. 3. ed. rev. ampl. Ijuí: Unijuí, 2016.

OLIVEIRA, M. K. Jovens e adultos como sujeitos de conhecimento e aprendizagem. 22a Reunião Anual da Anped, Caxambu, 1999.

REIS, D. B. O significado de permanência: explorando possibilidades a partir de Kant. In: CARMO, G. T. do (Org.). Sentido da permanência na educação de jovens e adultos: anúncio de uma construção coletiva. Rio de Janeiro: Tempo Brasileiro, 2016. p. 73-92.

SOBRAL. Lei n. 492, de 06 de janeiro de 2004. Dispõe sobre a Nucleação das Escolas da Rede Municipal de Ensino, e dá outras providências. Câmara Municipal de Sobral, 2004.

SOBRAL. Regimento Interno. Escola de Educação Infantil e Ensino Fundamental José Arimateia Alves, 2017a.

SOBRAL. Projeto Político Pedagógico. Escola de Educação Infantil e Ensino Fundamental José Arimateia Alves, $2017 \mathrm{~b}$.

Francisco Josimar Ricardo Xavier: Mestrando em Educação pela Universidade Federal Fluminense, UFF. Integra o Grupo de Pesquisa em Educação Matemática (GRUPEMAT), do Instituto de Educação de Angra dos Reis, IEAR/UFF e o Grupo de Etnomatemática da UFF (GETUFF).

ORCID: https://orcid.org/0000-0001-6376-2828

E-mail: josimar_xavier@id.uff.br

Adriano Vargas Freitas: Doutor em Educação Matemática pela Pontifícia Universidade Católica de São Paulo. Professor do Programa de Pós-Graduação em Educação da UFF. Professor no Instituto de Educação de Angra dos Reis. Desenvolve pesquisas relacionadas à Educação Matemática, Formação de Professores e Currículos direcionados a Educação de Jovens e Adultos.

ORCID: https://orcid.org/0000-0002-4602-3473

E-mail: adrianovargas@id.uff.br

Este periódico utiliza a licença Creative Commons Attribution 3.0, para periódicos de acesso aberto (Open Archives Iniciative - OAI). 